\title{
Challenging Infrastructure Project Assisted by Monitoring and Numerical Modelling as the Follo Line Tunnels were Excavated Below Existing Tunnels
}

\author{
Nghia Quoc Trinh ${ }^{1}$ (D) Kristin Hilde Holmøy ${ }^{2} \cdot$ Hanne Elisabeth Wiig ${ }^{3}$
}

Received: 12 August 2020 / Accepted: 7 January 2021 / Published online: 5 February 2021

(c) The Author(s) 2021

\begin{abstract}
Just south of Oslo Central Station, the new high-speed Follo Line railway tunnels pass beneath the existing Ekeberg road tunnels. This paper presents the construction methods, numerical model, and monitoring program used to assess the stability of the E6 road tunnels during the excavation of the Follo Line tunnels only a few metres below. The construction of the Follo Line was approved subject to three conditions: (1) there should be no negative effect on the stability of the Ekeberg tunnels, (2) the traffic flow in the Ekeberg tunnels had to be maintained at all times and (3) any risk of instability in the existing tunnels must be detected beforehand, so that necessary precautionary actions could be taken in good time. To deal with the challenges, SINTEF developed a comprehensive analysis procedure, combining continuous rock stress measurements and displacement measurements with 2D and 3D numerical modelling. The rock stress change monitoring was used together with the numerical model to monitor the stability conditions in the Ekeberg tunnels as the Follo Line tunnels were excavated. This ensured that any risk of instability in the existing tunnels could be detected in advance to enable precautionary action to be taken. The successful completion of the new tunnels without any disturbance to the road tunnels shows that the procedure would be useful for dealing with similar applications in the future.
\end{abstract}

Keywords Railway tunnel $\cdot$ Numerical model $\cdot$ Tunnel construction $\cdot$ Monitoring

\section{Introduction}

In 2013, Bane NOR (Norwegian National Rail Administration) decided to construct the Follo Line Project, a new high-speed railway connecting Oslo and Ski. The Follo Line tunnels are designed for speeds up to $250 \mathrm{~km} / \mathrm{h}$ and will form part of the future Oslo-Gothenburg high-speed railway (Kruse 2017). The project comprises a $22-\mathrm{km}$ long twin tunnel, each tunnel being $9.5 \mathrm{~m}$ in diameter. The tunnels have been excavated in rock using tunnel boring machines (TBMs) for $18.5 \mathrm{~km}$ and by 'drill and blast' and 'drill and split' methods in the remaining length towards Oslo Central Station. Here the tunnels are also in rock and pass under the existing Ekeberg road tunnels, which are part of the

Nghia Quoc Trinh nghia.trinh@sintef.no

SINTEF, Trondheim, Norway

2 NGI, Trondheim, Norway

3 BaneNOR, Oslo, Norway
European highway road-E6. The main construction phase commenced in 2015 and is scheduled for completion at the end of 2022. In 2015, the estimated cost of the project was 25 billion Norwegian kroner (NOK) (Kruse 2017). The location and layout of the Follo Line project and the junction is shown in Fig. 1.

This paper presents the construction methods, numerical model, and monitoring program used to assess the stability during construction of the junction between Ekeberg tunnels and the Follo Line tunnels only a few metres below. This case is of special interest since a combination of "investigation", "numerical modelling", and "monitoring" were implemented smoothly to ensure the safety of new and existing tunnels.

\section{Junction Area in the Ekeberg Hill}

The junction area is located in the Ekeberg hill close to Oslo Central Station. Here the Follo Line tunnels consist of three tunnels which also merge together creating a $30 \mathrm{~m}$ 


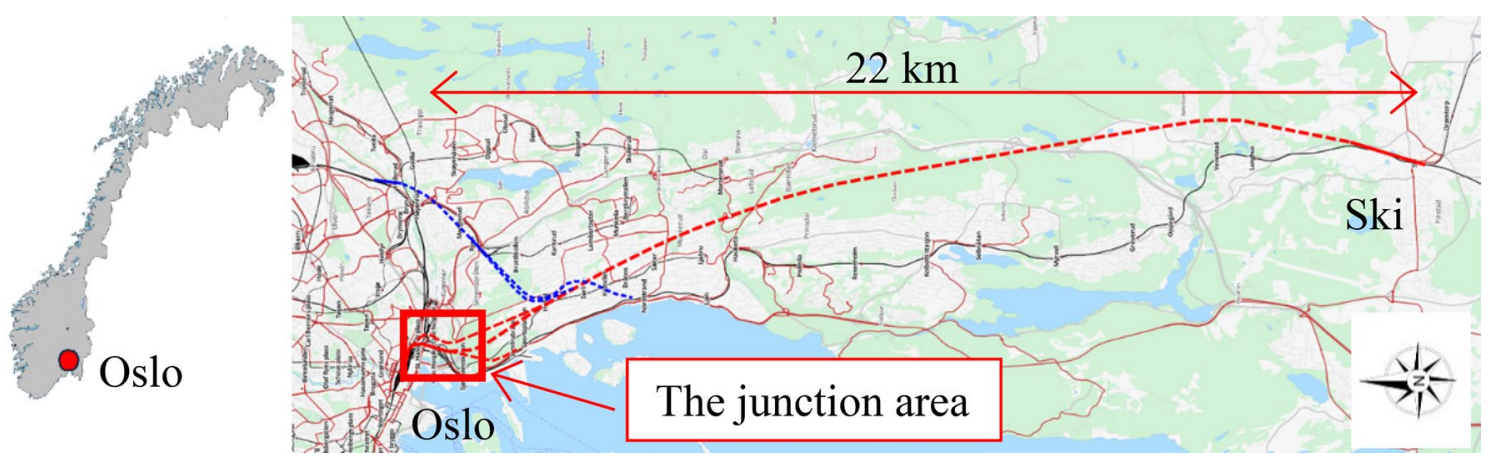

Fig. 1 Location and plan view of general layout of the project. Junction between Follo Line and Ekeberg tunnels is also indicated

span cavern in the approach to the Station. The main tunnels are:

- Inbound Østfold Line (IØL).

- Inbound Follo Line (IFL).

- Outbound Follo Line (OFL).

- The merged part is referred to as the three-track tunnel (3TT).

In the junction area, the Follo Line tunnels pass beneath the existing Ekeberg road tunnels and a sewage tunnel (Alna River tunnel) with very small clearances. The road tunnels comprise two central main tunnels and two 'slip-road' tunnels, one on each side, at a higher elevation. The minimum theoretical vertical distance between the Follo Line tunnels and the two main Ekeberg road tunnels is less than $4 \mathrm{~m}$. This makes the intersection very complicated, as shown in Figs. 2 and 3. In addition, the Ekeberg tunnel is one of the most trafficked roads in and out of Oslo (with more than 75000 cars passing annually) and any interruption to the traffic was a major concern. As a result, the construction of the Follo Line tunnels had to satisfy the following requirements from the owner of the existing traffic tunnels (Norwegian Road Authority-SVV):

- No negative effect on the stability of the Ekeberg tunnels.

- No interruption to traffic flow in the Ekeberg tunnels.

- This meant that the stability of the existing tunnels had to be ensured at all times. Any risk of instability in the existing tunnels had to be detected beforehand so that preventative measures could be put in place.

To meet these strict requirements, a careful plan of excavation and rock support was designed and implemented, particularly for the section under the Ekeberg tunnels.

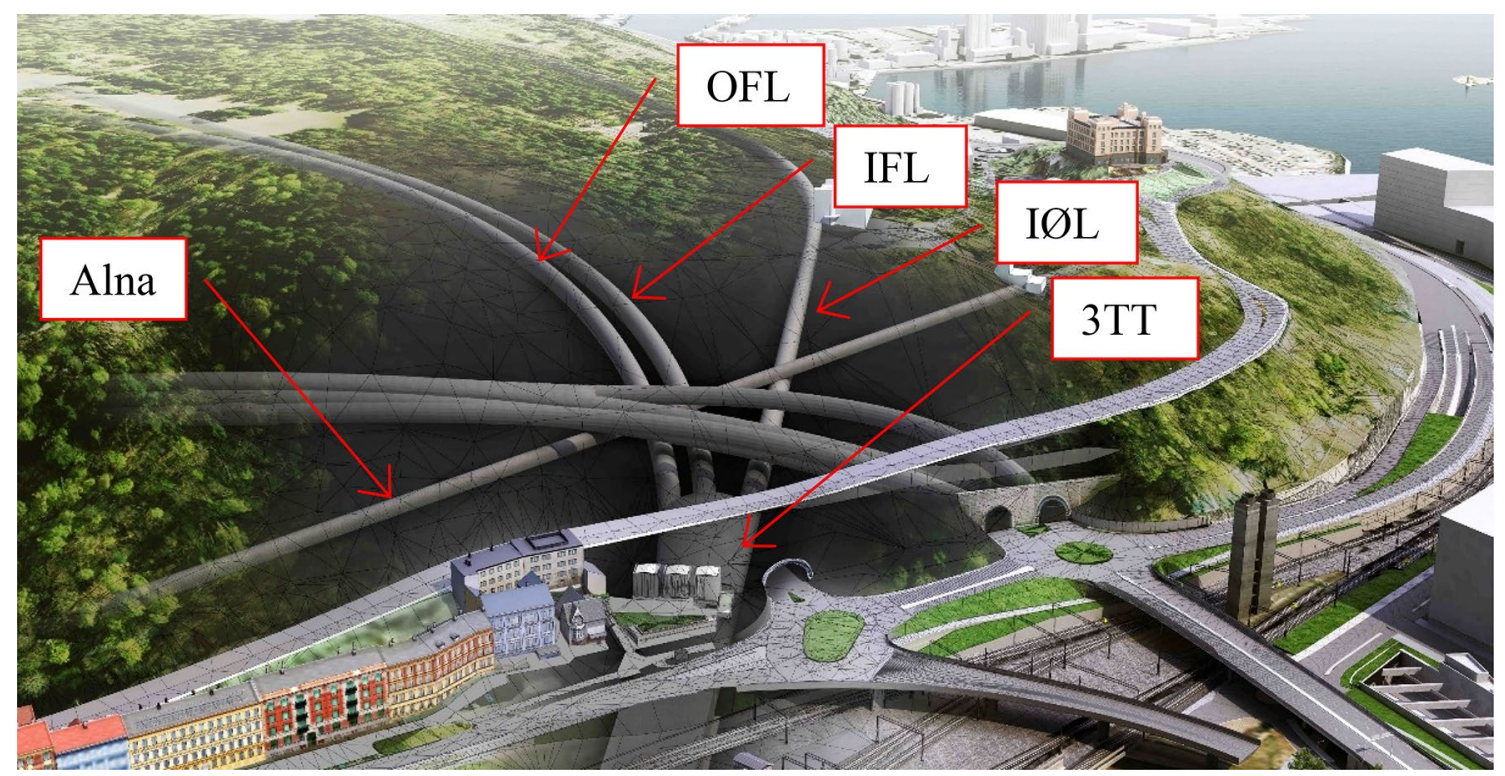

Fig. 2 Junction between Ekeberg tunnels (existing) and the Follo Line tunnels (OFL, IFL, IØL, and 3TT) 


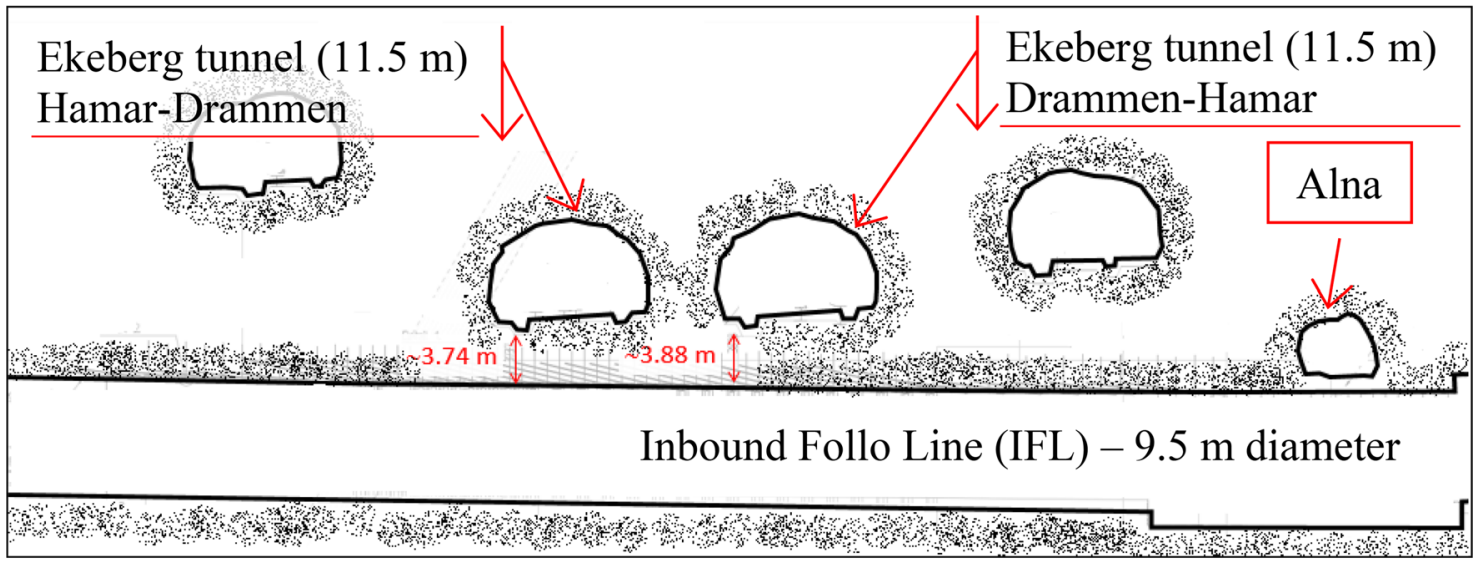

Fig. 3 Longitudinal section along the Inbound Follo Line

The excavation method specified for the area under the Ekeberg tunnels was "drill and split". This is a mechanical method for breaking/excavating rock. Briefly, the method involves drilling holes in the rock mass to be excavated, then using mechanical force to split the rock and finally using a mechanical hammer to loosen the remaining rock from the rock face (Lawton et al. 2017). The method is highly applicable in places where there are strict vibration limits and in situations within a short distance of other construction works or infrastructure where blasting is forbidden.

Excavation of the IØL tunnel was carried out first to gain quick access to the large span three-track tunnel. Excavation method in this tunnel was "drill and split", full face. Information of the rock mass behaviour and stability of the junction during construction of this tunnel was carefully evaluated and used as one of the important sources for the verification of the 3D numerical model. The rock mass behaviour and results of 3D the model were followed and compared at every excavation round.

For the IFL tunnel, the "drill and split" excavation procedure entailed driving a top-heading first, with the benching following approximately $15 \mathrm{~m}$ behind the topheading face. The OFL tunnel was excavated by the "drill and split" method with full face, as for the IØL tunnel. The tunnelling face in one tunnel was always $10-20 \mathrm{~m}$ in front of the other tunnel. The excavation method in this area can be seen in Fig. 4 and summarised as follows:

- Inbound Østfold Line (IØL): full face excavation. "Drill and blast" outside the critical area, and "drill and split" under the Ekeberg tunnels.

- Inbound Follo Line (IFL): top heading and benching. "Drill and blast" outside the critical area, and "drill and split" under the Ekeberg tunnels.
- Outbound Follo Line (OFL): full face excavation. "Drill and blast" outside the critical area, and "drill and split" under the Ekeberg tunnels.

- The merged part, referred to as the three-track tunnel (3TT): "Drill and blast" was used with multi partial stages due to large span. "Drill and split" was only in a small part of this tunnel.

In addition to the particular excavation methods, a special rock support was designed. This comprised:

- spiling bolts: $L=8 \mathrm{~m}$, in-row spacing $=20 \mathrm{~cm}$, row-torow spacing $=2 \mathrm{~m}$;

- radial bolts: $L=3 \mathrm{~m}$, in-row spacing $=80 \mathrm{~cm}$, row-to-row spacing $=1 \mathrm{~m}$;

- lattice girders: spacing $1 \mathrm{~m}$.

The above rock support was applied for the most critical section (underneath the Ekeberg tunnels). In less critical sections, the spacing of the bolts and lattice girders was slightly increased.

\section{Geological Conditions and Investigations}

Several site investigations were carried out in advance of the tender stage. These are summarized in the Engineering Geology and Hydrogeological Disciplinary Report (Jakobsen 2017), the most important being:

- seismic refraction.

- resistivity measurements and structural geological mapping.

- engineering geological mapping on the surface and in existing nearby tunnels. 


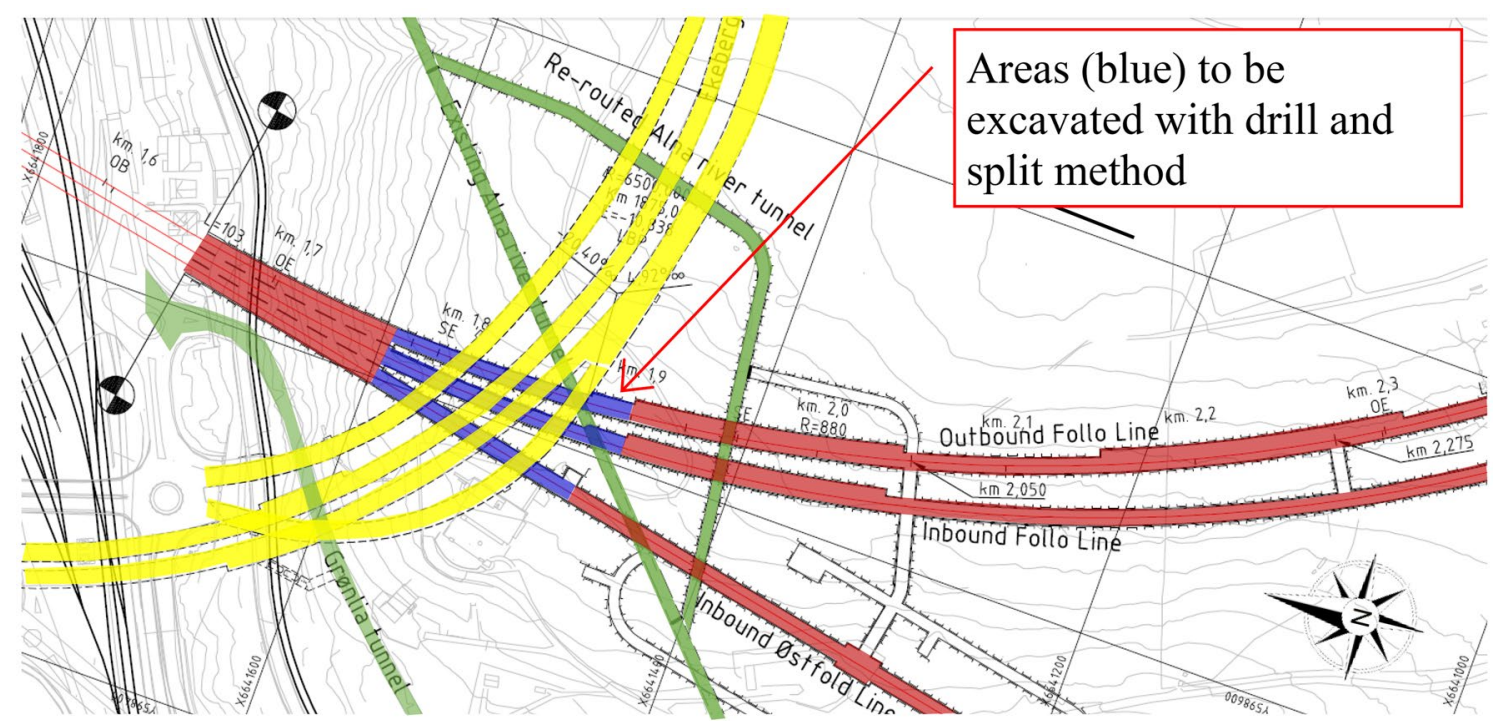

Fig. 4 Area with "drill and split" excavation method (green area)

- laboratory testing of rock mass samples.

- hydrogeological mapping on the surface.

- in situ rock stress measurements.

The engineering geological map in Fig. 5 shows the area of interest, with the existing Ekeberg tunnels and the IFL, OFL, IØL, and 3TT tunnels. The dominating rock type is Precambrian granitic gneiss. To the northeast, the Follo Line tunnels cross a major fault zone and weakness zone with rock types such as alum shale and syenite porphyry. The fault zone represents the boundary between the Oslo region with sedimentary rocks of Cambrian to Silurian age, and the Precambrian rocks further southeast. The fault zone is presented as a boundary line between Cambro-Silurian rocks and Precambrian rocks in Fig. 5. The fault zone is located at the outer edge of the area of interest and was, therefore, not included in the numerical modelling presented in this paper. The fault zone was not expected to directly influence the area where the Follo Line tunnels pass below the Ekeberg tunnels. In this area, the rock is granitic gneiss. However, the fault zone may influence the in situ stresses.

A weakness zone, oriented east-west and 1-5 m wide, was expected to cross the centre of the 3D model, as shown in Fig. 5. This weakness zone was included geometrically in the 3D model, but not as a continuous weakness zone. This is due to observations of the weakness zone in the existing Ekeberg tunnels and in rock outcrops on slopes showing to be not planar and of varying width. The weakness zone is undulating and narrow and has almost no thickness over short sections. Consequently, the stability of the tunnel excavations would only be locally affected. Nevertheless, extra rock support was expected to be point-wise needed.
The general rock mass quality is medium, with a $Q$ value between 4 and 10, and has two dominating joint sets:

- strike north-south with dip $35^{\circ}-90^{\circ}$ towards west (foliation).

- strike east-west with steep dip.

\section{Numerical Model}

\subsection{Model Set-Up and Simulation Process}

To provide information for decision-makers, a comprehensive three-dimensional (3D) numerical model was established for this particular junction. The objectives of the numerical model were:

- to evaluate the stability of the junction area for a given construction layout, excavation method, and rock support measures.

- to provide a reliable forecast tool for planning and especially during construction for early identification of possible risks.

Establishment of the 3D numerical model was based on geometrical scanning of the existing tunnels, the detailed geometrical design of the new tunnels, and the most updated construction layout, schedule, and method.

The excavation method was conventional "drill and blast" in the area outside the existing road tunnels. Near or under the existing tunnels, the "drill and split" excavation method was specified to minimise damage to the rock mass around 


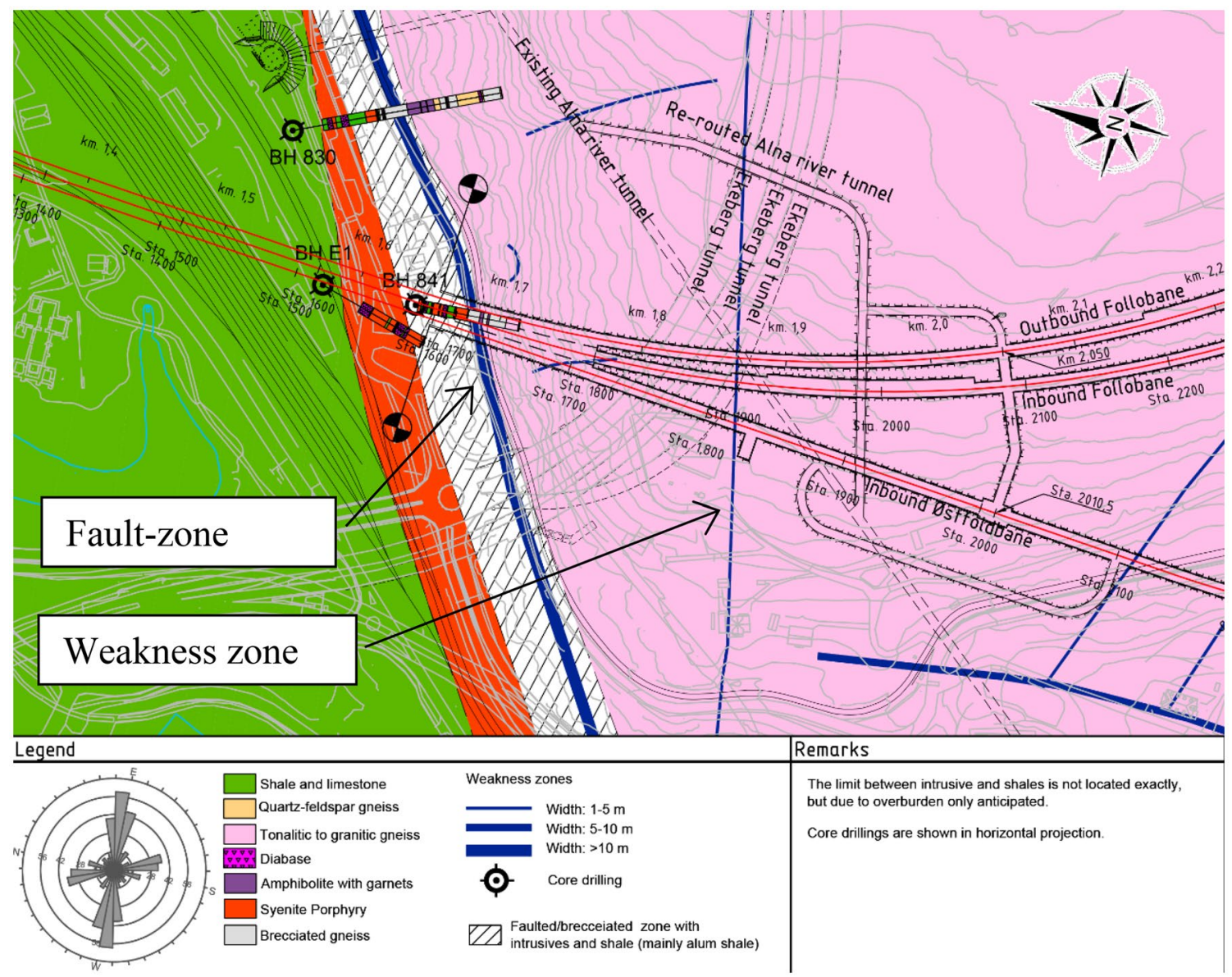

Fig. 5 Engineering geological map showing the area of interest for the numerical model

the tunnel. In the "drill and blast" sections, a pull length of $5 \mathrm{~m}$ for each blasting round was normally used. In the "drill and split" section, a pull length of $2.5 \mathrm{~m}$ was used for each splitting round. Thus, in the model geometry, the Follo Line tunnels were divided into $5 \mathrm{~m}$ and $2.5 \mathrm{~m}$ lengths in the "drill and blast" and "drill and split" sections, respectively. In this way, every excavation step was simulated to obtain the full evolution of stresses and displacements in the rock mass from the start of the construction process. To facilitate such detailed model, the smallest size of the element was $0.2 \mathrm{~m}$ (i.e. $200 \mathrm{~mm}$ ) — in the tunnel area, and the largest size was approximately $10 \mathrm{~m}$ at the boundaries of the model. Number of elements was almost 4.5 million elements. Top of the model was at elevation $+70 \mathrm{~m}$ above sea level, and bottom of the model was at elevation $-70 \mathrm{~m}$ above sea level. Material used in this model was elasto-plastic material, with Mohr-Coulomb failure criterion.

To simulate all excavation stages in the area, including (a) the natural state condition, (b) the existing stage with the old tunnels, and (c) the changes in stresses and displacements within the rock mass during the excavation of the new tunnels, the simulation process was performed as follows:
- Simulation 1: no excavation in the model - to obtain the natural in situ stress condition within the site.

- Simulation 2: all the existing tunnels were excavated to model the existing condition prior to the construction of the Follo Line tunnels. This was to obtain the existing stress situation and deformation for comparison with the observations and 2D measurements in the existing tunnels. This provided an early calibration of the model.

- Simulation 3: this was the most complex simulation of the simulation process, where all the planned excavation steps and sequences were strictly reproduced.

o The Inbound Østfold Line (IØL) was simulated with 63 excavation steps, including $5 \mathrm{~m}$ "drill and blast" pull lengths, and $2.5 \mathrm{~m}$ "drill and split" pull lengths.

o The Inbound Follo Line (IFL) and Outbound Follo Line (OFL) were simulated as parallel excavations, with about $15 \mathrm{~m}$ lag between the tunnelling faces in the two tunnels. A total of 58 simulation steps were carried out to model 58 excavation steps, including "drill and blast" and "drill and split" excavation methods. 
o The three-track tunnel (3TT) was simulated with 65 simulation steps to model a complicated layout and sequenced excavation.

The layout of the 3D numerical model for the junction is presented in Fig. 6.

After setting-up the model, input parameters for the model were carefully evaluated and obtained.

\subsection{Rock Stress Measurement and In situ Rock Stress}

Before excavation started, SINTEF carried out stress measurements in 2011 and 2012. During construction of the Inbound Østfold Line (IØL) tunnel in 2016, when the tunnelling face was at chainage 1890, a 3D-stress measurement was carried out to obtain the in situ stress condition at the site. The measuring method was the over-coring method, as described in Trinh et al. (2016). The measurements in 2011 and 2012 were 3D- and 2D-stress measurements, respectively. The location of the 2011 measurement was at Ekeberghallene in the Ekeberg rock cavern, which is about $1200 \mathrm{~m}$ south of the junction. The measurements in 2012 were taken at two locations: a pillar between the main Ekeberg tunnels, and in the pumping cavern of the Ekeberg tunnels.

The locations where the measurements were carried out in 2012 and 2016 are shown in Fig. 7. The 2011 stress measurements in the Ekeberg cavern are not presented in this figure as the location was about $1200 \mathrm{~m}$ south of the siteoutside the figure. Results from the 3D-stress measurements are given in Table 1.
The in situ stress level measured in 2016 was much higher than the measurements in 2011. In the 2016 measurement, $\sigma_{1}$ is twice and $\sigma_{3}$ is five times higher than the measurements in 2011. This may be explained by a local weakness zone in the rock mass or maybe by the presence of existing caverns/tunnels, such as the former Alna River tunnel which is not far from the locations of the 2016 measurements. Comprehensive calibrations of the numerical model using the results from the stress measurements in 2011 and 2016 were made during the planning and early construction stages of the Follo Line project. It was found that all the numerical model results with input from 3D-stress measurements in 2016 gave far higher values of stress than the results obtained from $2 \mathrm{D}$-stress measurements performed in the existing infrastructure, whilst with input from the 3D-stress measurement in 2011, the numerical model results fitted quite well with the 2D measurements. When calibrating the results from the numerical model with data from the monitoring equipment during the early construction stages, the same pattern was observed. An example of the stress calibration is shown in Fig. 8. Thus, it was decided that the results from the stress measurement in 2011 could be used as a representative in situ stress condition for input into the numerical model for this project. Therefore, the estimated in situ stress for the model is based on the measurement in 2011, as shown in Table 2.

\subsection{Rock Mass Properties}

During initial testing of the model and the first simulations, the input parameters for the rock mass properties were estimated based on geological mapping and laboratory tests.
Fig. 6 Configuration of the 3D-numerical model for the junction between Ekeberg and Follo Line tunnels

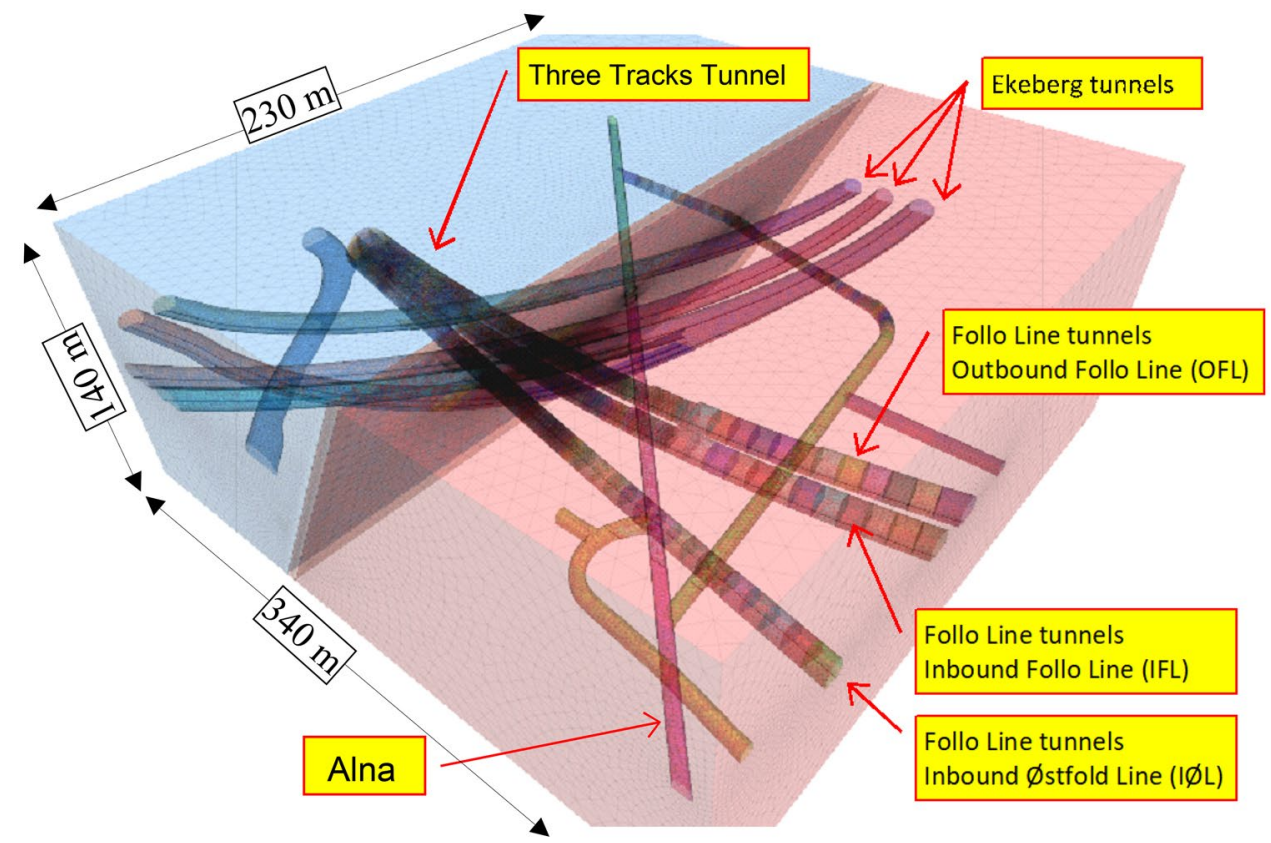




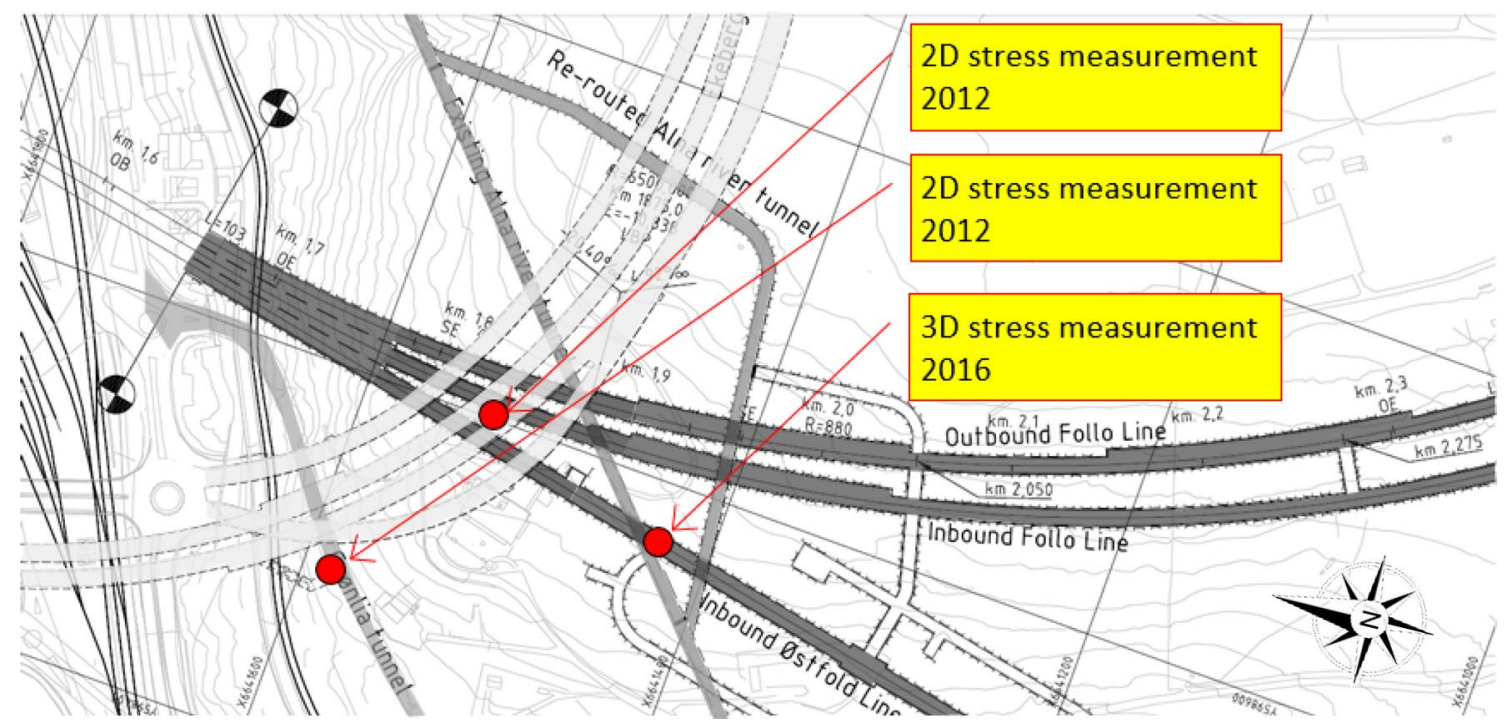

Fig. 7 Locations of the stress measurements before (2012) and during construction (2016)

Table 1 Results from 3D-stress measurements (SINTEF 2011, 2016)

\begin{tabular}{lllll}
\hline $\begin{array}{l}\text { Year of } \\
\text { measure- } \\
\text { ment }\end{array}$ & $\begin{array}{l}\text { Stress } \\
\text { compo- } \\
\text { nent }\end{array}$ & $\begin{array}{l}\text { Magnitude } \\
(\mathrm{MPa})\end{array}$ & $\begin{array}{l}\text { Dip direction } \\
\text { (degrees) }\end{array}$ & $\begin{array}{l}\text { Dip } \\
\text { (degrees) }\end{array}$ \\
\hline 2011 & $\sigma_{1}$ & $9.9 \pm 1.9$ & $\mathrm{~N} 248.4$ & $24^{\circ} \mathrm{SW}$ \\
& $\sigma_{2}$ & $7.5 \pm 1.9$ & $\mathrm{~N} 145.0$ & $27^{\circ} \mathrm{SE}$ \\
& $\sigma_{3}$ & $1.9 \pm 2.8$ & $\mathrm{~N} 14.0$ & $61^{\circ} \mathrm{SE}$ \\
2016 & $\sigma_{1}$ & $21.6 \pm 2.1$ & $\mathrm{~N} 338$ & $35^{\circ} \mathrm{SW}$ \\
& $\sigma_{2}$ & $17.3 \pm 3$ & $\mathrm{~N} 224$ & $27^{\circ} \mathrm{SE}$ \\
& $\sigma_{3}$ & $10.9 \pm 0.9$ & $\mathrm{~N} 104$ & $61^{\circ} \mathrm{SE}$ \\
\hline
\end{tabular}

The results of this model were verified with stress change and displacement data obtained so far from monitoring equipment at that time. During construction, a very comprehensive calibration and testing of the model was carried out based on the continuously collected data from the monitoring equipment. This calibration resulted in a slight update of the rock mass properties. The updated input parameters of the rock mass properties for the 3D numerical model are shown in Table 3.

\section{Results of Numerical Model Versus Monitoring}

\subsection{Locations of Monitoring Equipment}

A comprehensive monitoring program was established to obtain the information for numerical verification, but more crucially to monitor the behaviour of the rock mass between the existing Ekeberg tunnels and the new Follo Line tunnels
(Trinh et al. 2017). During construction of the new tunnels, stress and displacement of the rock mass developed as the excavation progressed. This development was monitored to evaluate the stability of both existing tunnels and tunnels under construction. Any unexpected evolution could also be detected at an early stage by means of this monitoring program.

Displacement was monitored using extensometers. In this project, the extensometer model A5 Rod-type (manufactured by Geokon) with four hydraulic anchors was used. For monitoring stress change, SINTEF used an in-housedeveloped special version of the "door-stopper"—called the long-term-door-stopper monitor (LTDM). The description of this device can be found in Trinh et al. (2016). The extensometers and LTDMs were installed well before the excavation approached the critical junction between the Follo Line tunnels and the Ekeberg tunnels.

In this project, it was very important to detect the stress and displacement changes at an early stage, long before any instability problem might appear. The purposes of getting early information were:

- to calibrate the numerical model and improve the model during the early construction phase so that the model became a reliable tool for analysing the critical excavation stages-at close to or directly below the Ekeberg tunnels.

- the stress and displacement evolution in the rock mass could be monitored from the start, so that any "unexpected development" could be detected in good time for further study and action. 


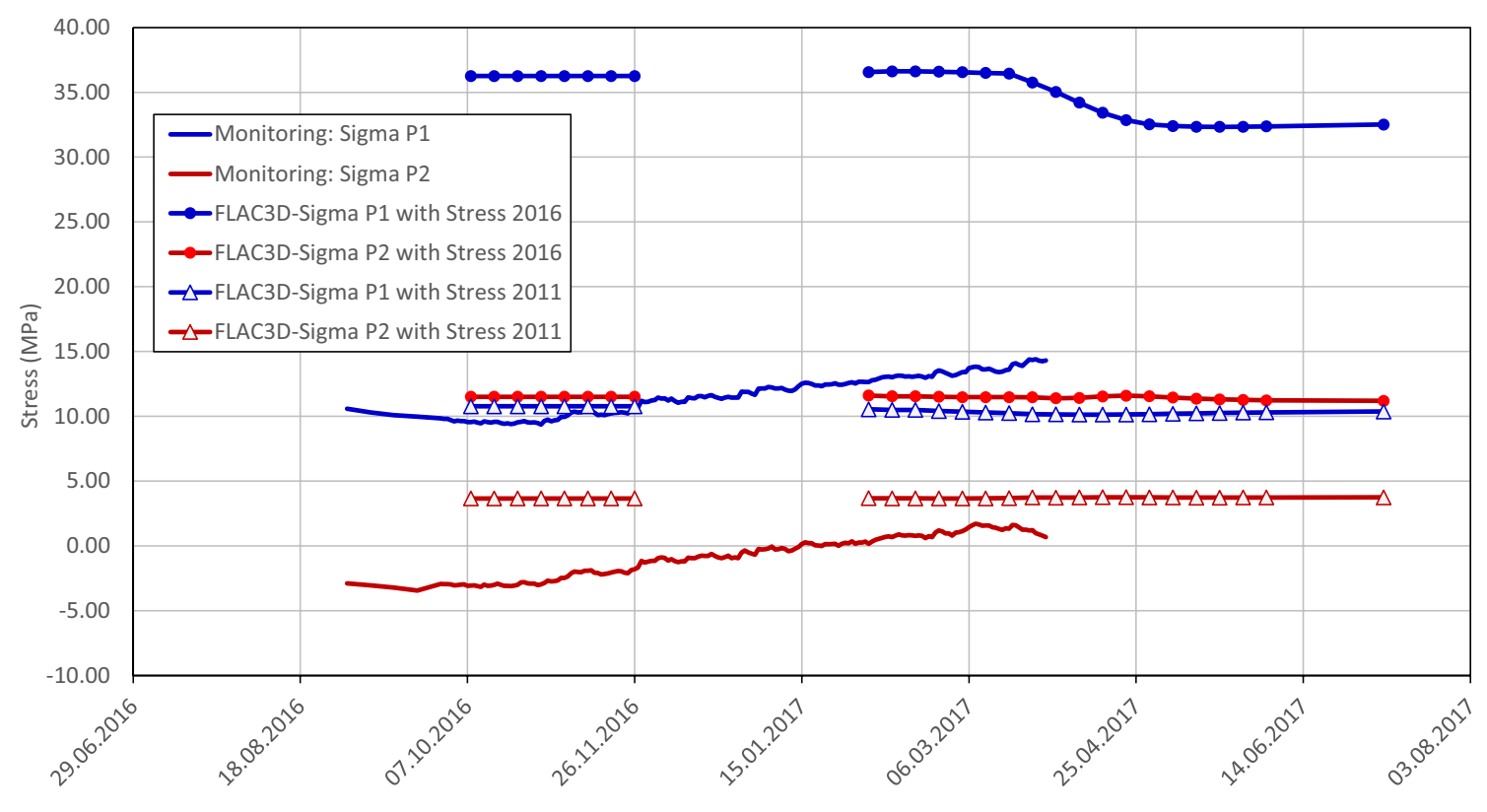

Date of measurement

Fig. 8 Example of stress calibration with data from monitoring equipment installed in a pillar in the Ekeberg tunnel

Table 2 In situ stress for the numerical model

\begin{tabular}{llll}
\hline In situ stress & $\begin{array}{l}\text { At level 0 } \\
(\mathrm{MPa})\end{array}$ & $\begin{array}{l}\text { Gradient } \\
(\mathrm{MPa} / \mathrm{m})\end{array}$ & Note \\
\hline$\sigma_{\mathrm{xx}}$ (east-west) & 10 & $0.0275^{*}(10 / 4.5)$ & \\
$\sigma_{\mathrm{yy}}$ (north-south) & 6 & $0.0275^{*}(6 / 4.5)$ & \\
$\sigma_{\mathrm{zz}}$ (vertical) & 4.5 & 0.0275 & \\
\hline
\end{tabular}

Considering the purpose of the monitoring, the monitoring equipment was carefully installed as soon as suitable locations became available. Some locations were available before construction (in the existing Ekeberg tunnels), but some locations only became available as excavation progressed (in the Follo Line tunnels).

The monitoring equipment was installed as described below:
- Long-term-door-stopper monitor (LTDM) in pillar"LTDM-Pillar": this stress device was installed in May 2015, when the excavation of the Follo Line tunnel was relatively distant from the Ekeberg tunnels. This LTDM was installed in a horizontal hole in a pillar and was almost above the centre line of the Outbound Follo Line (OFL) tunnel.

- "LTDM-Floor": this stress device was installed at the same time as the "LTDM-Pillar" (May 2015). It was installed in a vertical hole drilled downwards from the floor of a connection tunnel between the Ekeberg tunnels to the planned Inbound Follo Line (IFL) tunnel. This LDTM is almost above the centre line of the IFL tunnel.

- "Extensometer-Floor": this displacement device was installed at the same time as the LTDM-Pillar (May 2015). It was installed in a vertical hole drilled downwards from the floor of the same connecting tunnel
Table 3 Rock mass properties for the 3D numerical model

\begin{tabular}{llll}
\hline Parameter & Unit & Value & Note \\
\hline GSI & & 65 & From geological mapping \\
Uniaxial compressive strength & $\mathrm{MPa}$ & 117 & From laboratory tests \\
Poisson's ratio & & 0.15 & From laboratory tests \\
Rock mass Young's modulus (Em) & $\mathrm{MPa}$ & 10,000 & From a comprehensive calibration/verification \\
& & & using stress measurements and early monitoring \\
& & & results \\
Internal friction angle & Degrees & 55 & Estimated based on GSI \\
Cohesion & $\mathrm{MPa}$ & 2.0 & Estimated based on GSI \\
\hline
\end{tabular}


between the Ekeberg tunnels to the planned IFL tunnel. It is almost the same location as the "LTDM-Floor".

- "Extensometer-Niche": this displacement device was installed in March 2016. It was installed in a vertical hole drilled downwards from the floor of a SOS niche in the Ekeberg tunnels to the planned IØL tunnel.

- "LTDM-Roof 1": this stress device was installed in October 2016. At the time of installation, the excavation of the Inbound Østfold Line (IØL) had reached this location, and so the LTDM-Roof 1 was installed just a few metres behind the tunnel face. This LTDM was installed in a vertical hole drilled upwards from the roof of the IØL tunnel.

- "LTDM-Roof 2": this stress device was installed above the Inbound Follo Line (IFL) tunnel in November 2017. At the time of installation, the top heading excavation of the IFL tunnel had been completed. Thus, the LTDMRoof 2 was installed directly below the centre line of one of the main Ekeberg tunnels. This LTDM was installed in a vertical hole drilled upwards from the roof of the IFL tunnel.

- "LTDM-Roof 3": this stress device was installed in November 2017. At the time of installation, the top heading excavation of the Inbound Follo Line (IFL) had been completed. This LTDM was installed in a vertical hole drilled upwards from the roof of the three-track tunnel.

The locations and installations of the LTDMs and extensometers are summarised in Table 4 and shown in Fig. 9.

Unfortunately, the power cable connected to a station in the Ekeberg tunnels was accidently cut-off from June 2018 until October 2018. This station was responsible for the power supply to the equipment reading the data from "LTDM-Pillar", "LTDM-Floor", and "Extensometer-Floor" instruments. After reconnecting the power in October 2018, the data from the "LTDM-Pillar" became unstable and a large jump was exhibited by the "LTDM-Floor" data (as can be seen later in the Figs. 12 and 13). The data was considered to be unreliable as the stress change was significant and there was no excavation nearby to provide a possible explanation for it.

\subsection{Evolution of Stresses}

In the IFL and OFL tunnels, construction started from South and progressed northward. The first $65 \mathrm{~m}$ of both tunnels were excavated by conventional drill and blast with $5 \mathrm{~m}$ pull length. At a distance of approximately $40 \mathrm{~m}$ from the Ekeberg main tunnels, careful excavation using the drill and split method was implemented. More than 50 drill and split steps, each $2.5 \mathrm{~m}$ in length, were carried out. Critical construction in the IFL and OFL tunnels (directly under the Ekeberg tunnels) took place between February 2017 and February 2018.

The excavation plan was reproduced in the model to a large extent. The only difference was that in the model excavation was full face in all the tunnels, whilst in reality the IFL tunnel was excavated by top heading and benching. The model was simulated well before the critical construction stages were reached. During the drill and split excavation, it was planned that there would be a lag of $15 \mathrm{~m}$ distance between the tunnelling faces in the IFL and OFL tunnels, with the IFL tunnel progressing first. This lag distance was implemented in the model. Model results for $\sigma_{1}$ and $\sigma_{3}$ are presented in Figs. 10 and 11, which illustrate the stress distribution in a longitudinal section along the last part of the Inbound Follo Line (IFL). From the figures, the following comments can be made:

- the maximum stress component $\left(\sigma_{1}\right)$ around the tunnel increases from about $12 \mathrm{MPa}$ (in situ original condition) to $17.5 \mathrm{MPa}$. The incremental amount is approximately $5.5 \mathrm{MPa}$.

- the minimum stress component $\left(\sigma_{3}\right)$ around the tunnel decreases from about $5 \mathrm{MPa}$ (in situ original condition) to about $2.5 \mathrm{MPa}$. The reduction is approximately $2.5 \mathrm{MPa}$.

Table 4 List of monitoring equipment with installation time and configuration

\begin{tabular}{lll}
\hline Monitoring equipment & Time of installation & Location \\
\hline LTDM-Pillar & May 2015 & Horizontal in a pillar between the Ekeberg tunnels \\
LTDM-Floor & May 2015 & Vertical below the floor of a connection tunnel between the Ekeberg tunnels \\
Extensometer-Floor & May 2015 & Vertical below the floor of a connection tunnel between the Ekeberg tunnels \\
Extensometer-Niche & March 2016 & Vertical below the floor of a niche in the Ekeberg tunnels \\
LTDM-Roof 1 & October 2016 & Vertical above the Inbound Østfold Line (IØL) tunnel \\
LTDM-Roof 2 & November 2017 & Vertical above the Inbound Follo Line (IFL) tunnel, directly below one of \\
LTDM-Roof 3 & November 2017 & Vertical above the three-tracks tunnel
\end{tabular}




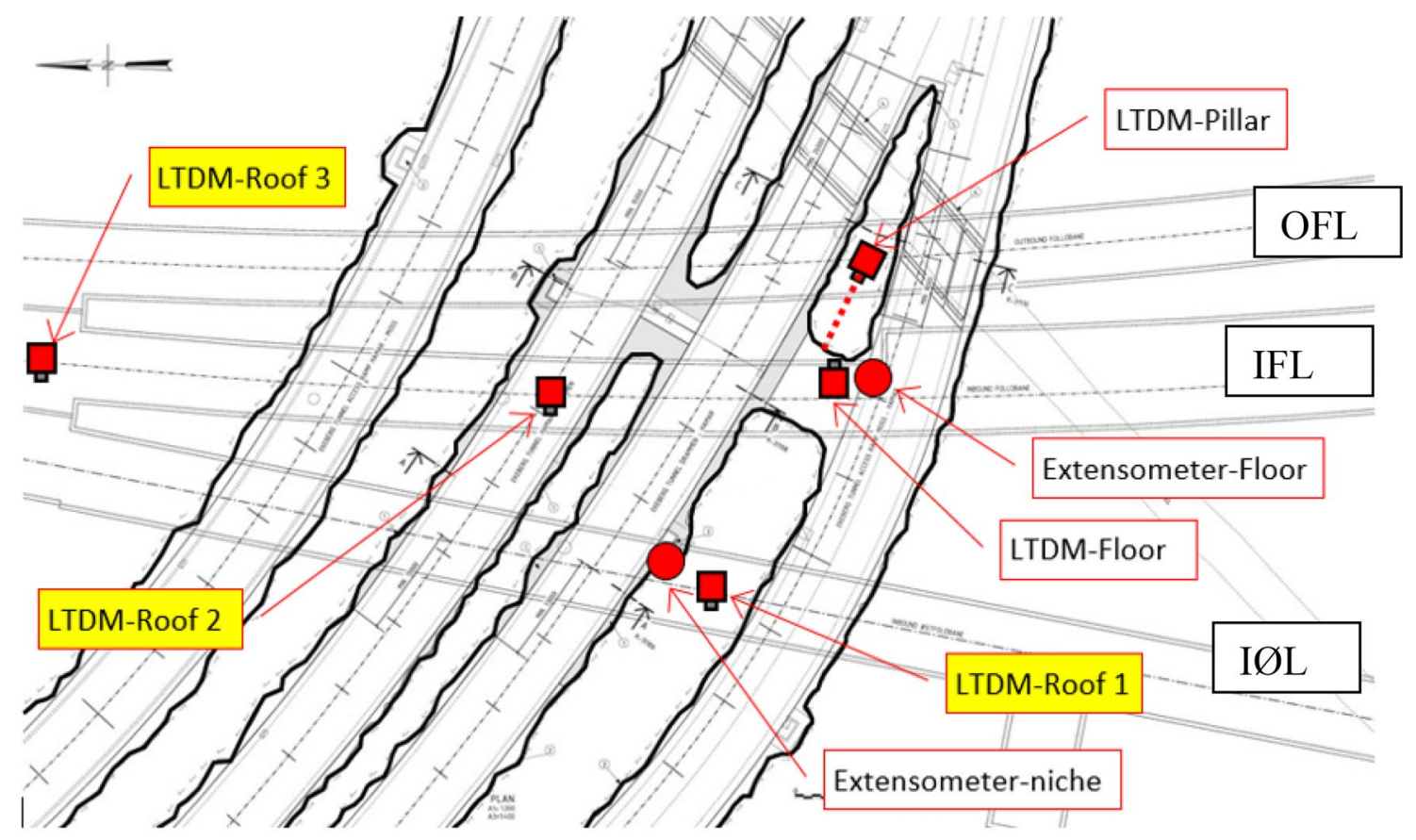

Fig. 9 Stress and displacement monitoring

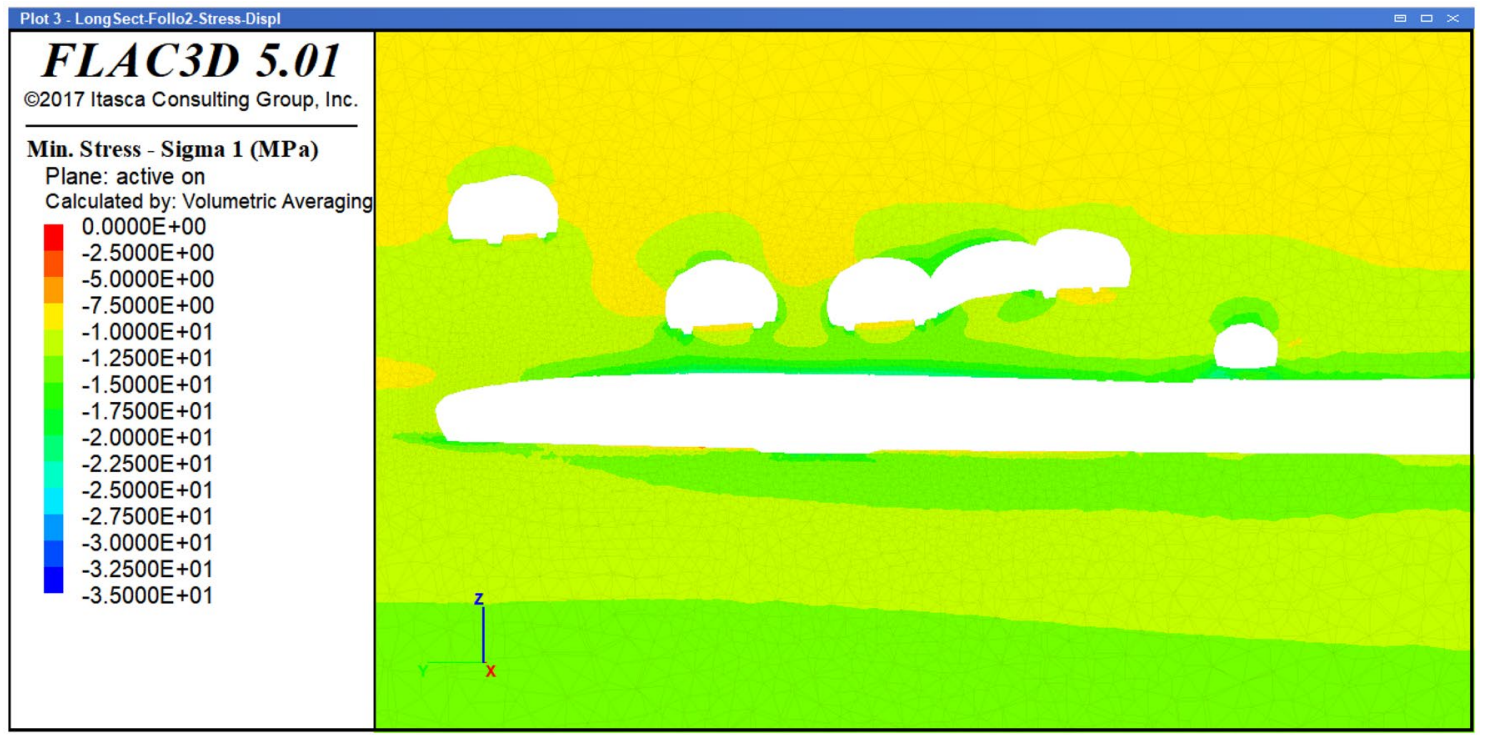

Fig. 10 Result of major principal stress at the junction after completion of all excavation-longitudinal section along IFL tunnel

Note that mathematical convention in the FLAC3D program is that compressive stresses have a negative sign and tensile stresses are positive. Thus, the engineering "major principal stress" is mathematical minimum stress and vice versa.

To compare the results from the numerical model against the stress data from the monitoring devices, the data from two critical LTDMs ("LTDM-Pillar" and
"LTDM-Floor"-see Fig. 9 for their locations) are presented herein. These two LTDMs were installed to monitor the stress evolution in the existing Ekeberg tunnels as a result of the excavation of the Follo Line tunnels. The LTDMs were installed at the most critical locations, where the Follo Line tunnels were at their closest to the Ekeberg tunnels-less than $4 \mathrm{~m}$ vertical distance. Both LTDMs were installed in May 2015, when the excavation of the Follo 


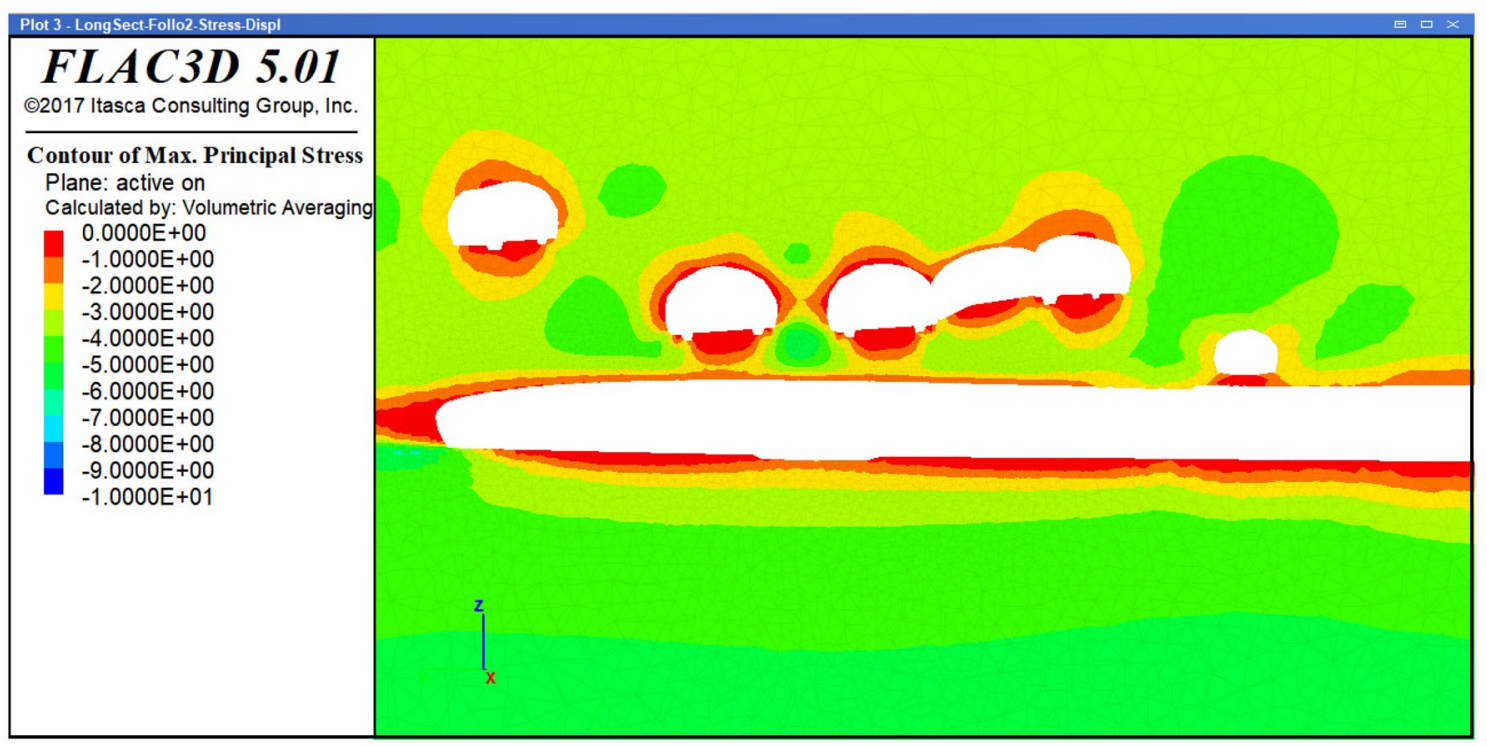

Fig. 11 Result of minor principal stress at the junction after completion of all excavation—longitudinal section along IFL tunnel

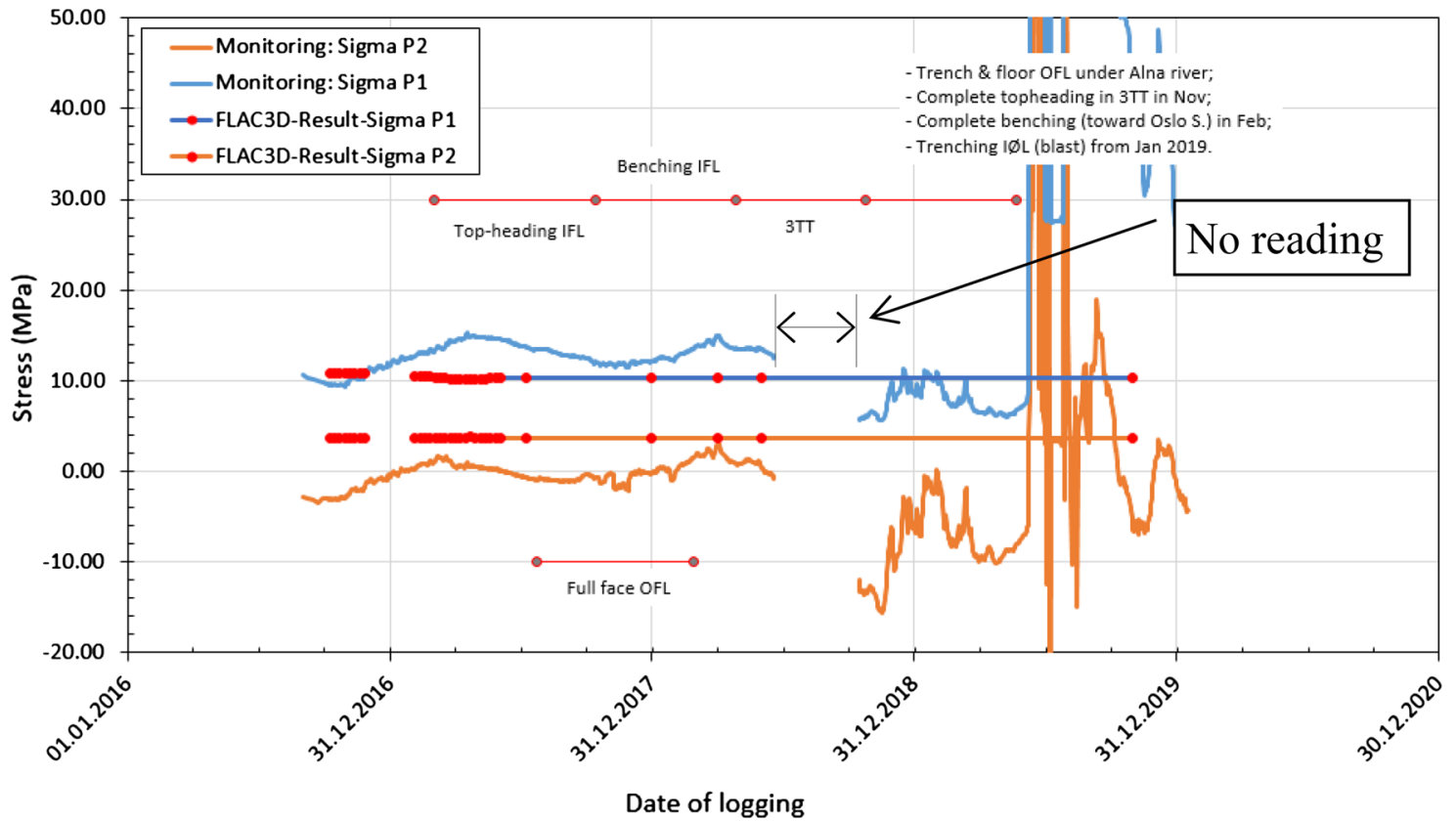

Fig. 12 Evolution of stress at location "LTDM-Pillar"—result from numerical model versus monitoring

Line tunnels was still a very long distance away (more than $150 \mathrm{~m}$ ) and, therefore, having practically no influence on the Ekeberg tunnels. Early installation of the LTDMs provided a good possibility of obtaining, from the start, the evolution of induced stress in the Ekeberg tunnels as the excavation of the Follo Line tunnels approached. Any abnormal change or evolution of stresses during the excavation progression could be detected early enough to implement appropriate precautionary measures, if necessary. The early monitoring data were also used for model verification.

The results from the numerical model and the recorded data at the LTDM-Pillar are shown in Fig. 12, and they fit relatively well. It can be seen that the numerical model predicts an almost constant evolution of the maximum inplane-stress $\left(\sigma_{\mathrm{P} 1}\right)$ at about $10 \mathrm{MPa}$, whilst the recorded data show that the stress was in the range 10-15 MPa with small changes during the construction phase. A similar 


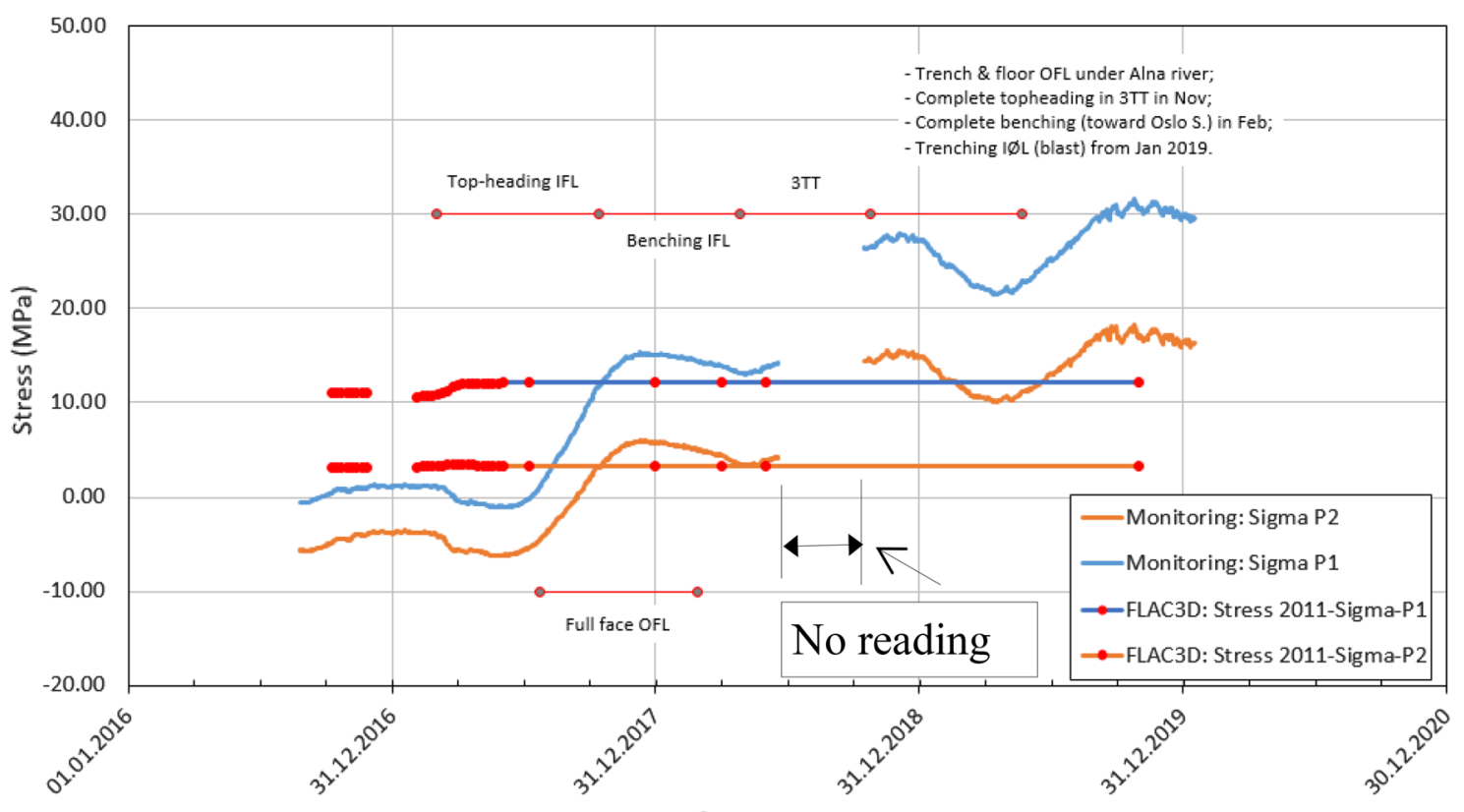

Date of measurement

Fig. 13 Evolution of stress at location "LTDM-Floor"-result from numerical model versus monitoring

result was observed for the evolution of the minimum inplane-stress $\left(\sigma_{\mathrm{P} 2}\right)$.

However, there were few details that need to be discussed:

- The numerical model predicts almost no stress changes, and there is a $5 \mathrm{MPa}$ change in both monitored stress. Lines showing evolution of both stresses were almost parallel, indicating the same amount and tendency of stress change. The stress change during mid-2016 to mid-2018 (before no-reading period) had two high peaks in Mar-April and two low peaks in NovemberDecember. The stress evolution had certain link to the excavation activities, but the numerical model seemed not be able to reflect this evolution. However, due to the fact that the difference was only about $5 \mathrm{MPa}$, results from the numerical model was accepted from practical point of view. It is probably that this issue needs to be further investigated and improved.

- The negative values of $\sigma_{\mathrm{P} 2}$ before the no readings period: when installing the "LTDM-Pillar", result of the initial measurement already indicated very low $\sigma_{\mathrm{P} 2}$ in this pillar (negative $\sigma_{\mathrm{P} 2}$ at the beginning). Logged data showed that this low stress condition was not improved during the excavation.

- "LTDM-Pillar" device was not reliable after the "no readings" period: after more than 100 days without electricity (from June to October 2018), the device was reconnected in mid-October 2018. After reconnecting, the logged data from the "LTDM-Pillar" showed a significant fluctuation. There was no significant excavation activity nearby to explain for this, especially after May 2019. A careful data investigation was carried out, and it was concluded that the "LTDM-Pillar" was not function properly after a long period without electricity. Thus, the logged data were not reliable.

The model results versus the monitoring data for the "LTDM-Floor" are presented in Fig. 13. As can be seen from the figure, the model results for $\sigma_{\mathrm{P} 1}$ and $\sigma_{\mathrm{P} 2}$ did not fit well before September 2017. During this period, the model prediction for $\sigma_{\mathrm{P} 1}$ was more than $10 \mathrm{MPa}$, whilst the monitoring data recorded a value of only approximately zero. Similarly, $\sigma_{\mathrm{P} 2}$ in the model was about $3 \mathrm{MPa}$, while the monitoring data gave a value of approximately - $5 \mathrm{MPa}$ (tension). In September 2017, the full-face excavation in the OFL tunnel and the benching in the IFL tunnel had progressed close to the "LTDM-Floor" location. The distance measured on plane view was only 15-20 m. After September 2017, the stress in this location quickly increased, and the model results fitted better with the monitoring data.

It is not easy to explain the behaviour of the stress evolution at this location. A possible explanation relates to the rock jointing and stress state at this particular stress monitoring location. The stress sensors seemed to be attached to a rock block with unfavourable joint orientations that initially caused the rock block to be somewhat free of surrounding stresses. When the excavation progressed towards 
this location, the stresses in the rock mass increased and the joints closed. As more contact with the surrounding rock mass developed, stresses started to be transferred from the surrounding rock mass to the rock block. The stress in the block quickly built up from a "free stress" condition to the same stress state as the surrounding rock mass. The rapid increase in stress monitored between July and September 2017 would be an evidence of this process. Similar to the "LTDM-Pillar", the data from "LTDM-Floor" seemed not reliable after reconnecting the electricity (with a large data jump right after the connection of electricity).

After studying the model results and the monitoring data, it can be stated from a practical point of view that the model results are comparable with the monitoring data for both LTDMs. The fit between the model results and the monitoring data is relatively good for both the magnitude and the pattern of the evolution of stress.

\subsection{Evolution of Displacements}

As described earlier, the stability of the Ekeberg tunnels was also monitored using extensometers. Two extensometers were installed-"Extensometer-Niche" and "ExtensometerFloor" (refer to Fig. 9 for their locations). The "Extensometer-Floor" was more critical as it was located at a somewhat larger excavation span where the vertical distance to the Ekeberg tunnels was smaller. Thus, the displacement monitored at this extensometer is interesting to analyse and compare with results from the numerical model.

To facilitate the comparison, the location of the extensometer was identified accurately to the correspondent element (or zone) in the numerical model, and the displacement from that element was determined for every simulation step.
During early construction phase, displacement result from each simulation step was verified with data from the extensometer at correspondent excavation progress. The model was then simulated further for forecasting the displacement and stress of the junction area during critical excavation steps and for decision-making during construction. Figure 14 shows the numerical model results for the IFL tunnel at one of the critical excavation steps.

The excavation work for the Follo Line tunnels was completed in July 2019. The continuous monitoring over a period of several years, covering the pre-construction and excavation stages has provided an extensive data record to compare with the numerical model results. Figure 15 shows the recorded monitoring data from the "Extensometer-Floor" and the results from the numerical model over the whole excavation period, bearing in mind that the critical excavation period was from February 2017 to February 2018. To evaluate the role and reliability of the numerical model, the displacement data in Fig. 15 can be divided into 3 periods, as follows:

Period 1-Before September 2017: this period includes both the non-critical excavation stages and part of the critical excavation stage which started in February 2017 with the top heading. During the non-critical excavation stages when excavation was relatively far from the junction, the displacement results from the numerical model fit well with the monitoring data. During the critical excavation stage, the numerical model displacement prediction was approximately $0.5 \mathrm{~mm}$ greater than that from the monitoring data. This numerical model result was accepted due to (a) the difference being only $0.5 \mathrm{~mm}$, (b) the model result and monitoring data show the same evolution pattern, and (c) full face

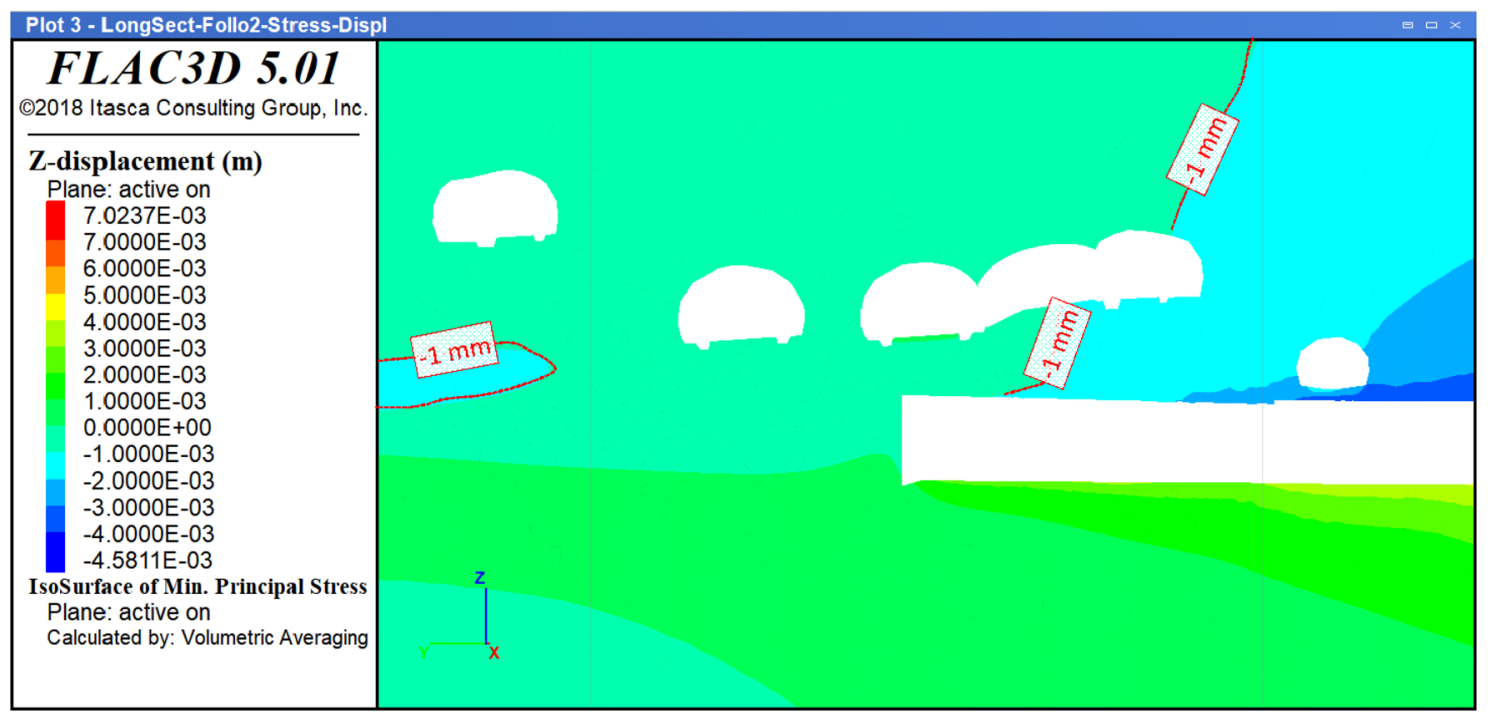

Fig. 14 Result of vertical displacement at the junction at critical excavation stage-longitudinal section along IFL tunnel 


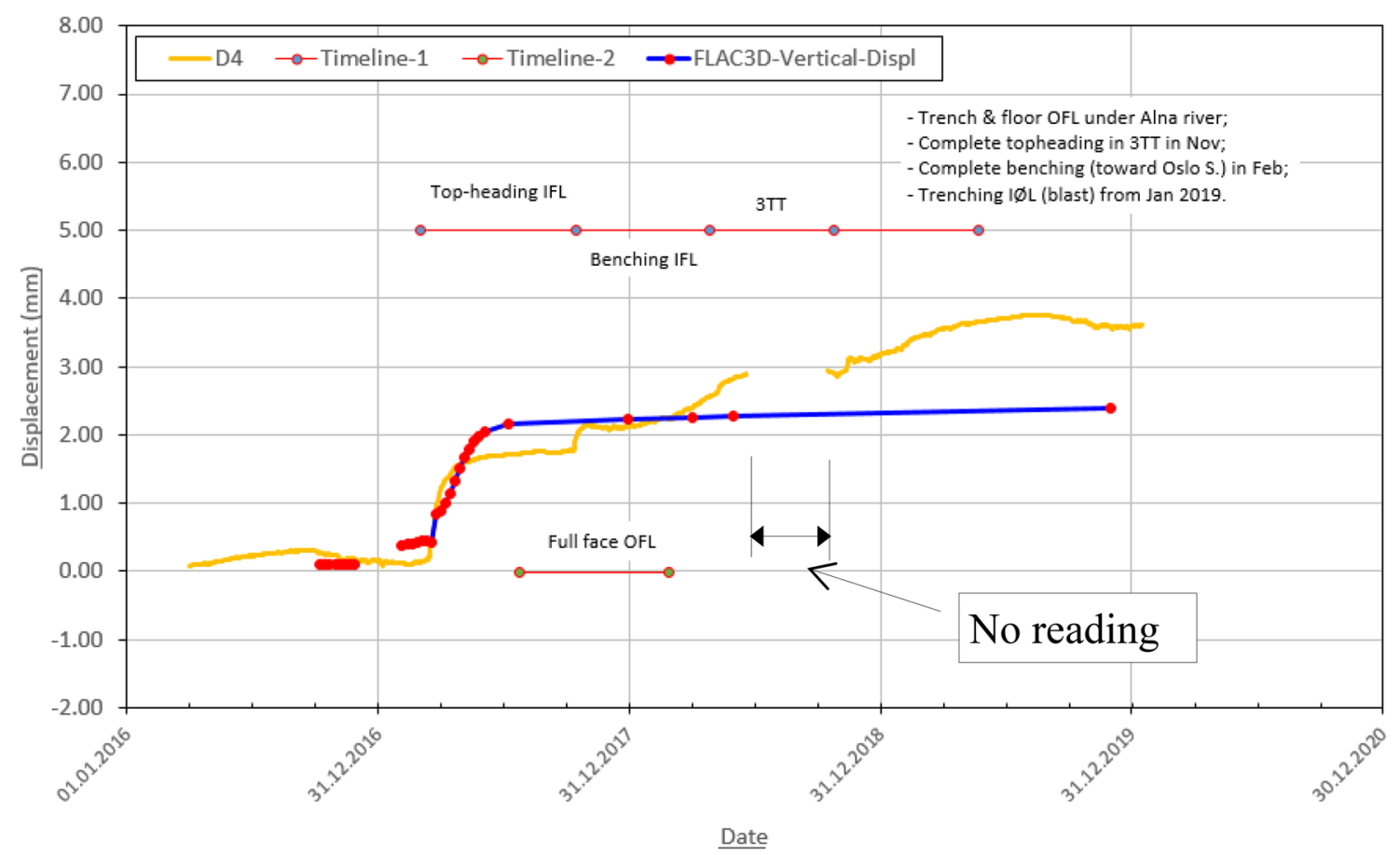

Fig. 15 Evolution of displacement at location "Extensometer-Floor"—-result from numerical model versus monitoring

excavation was implemented in the model whilst in reality only top heading excavation was carried out.

Period 2-Between September 2017 and March 2018: during this period, the benching in the IFL tunnel was executed producing full face conditions as simulated in the numerical model. The results from the numerical model and the recorded data were almost identical during this period, which demonstrates a very good match between the numerical model and the actual recorded data. With this accuracy, the numerical model was proven to be a reliable and an important tool for evaluating the stability condition at the junction during the critical excavation stage.

Period 3-After March 2018: critical excavation had already been completed in February 2018, and after March 2018, the excavation activities were (a) at three-track tunnel (3TT) with approximately $30 \mathrm{~m}$ span, and (b) excavation of a small trench in the floor of the OFL and IFL tunnels by drill and blast. During this period, the numerical prediction gave $1.0-1.5 \mathrm{~mm}$ displacement less than that from the monitoring data. It seems that the numerical model was unable to fully calculate the displacement caused by drill and blast in the three-track tunnel (3TT), which was approximately $100 \mathrm{~m}$ away from the extensometer. Studying the excavation progress in the $3 \mathrm{TT}$ and the monitoring readings during the same period, the displacement caused by the 3TT excavation was estimated to be approximately $0.5 \mathrm{~mm}$ at the "Extensometer-Floor" location. The additional $1 \mathrm{~mm}$ displacement recorded at "Extensometer-Floor" occurred during the excavation of the trench in the floor of the OFL and IFL tunnels. This excavation was by drill and blast, directly below the extensometer. Even though the size of the trench was only $1 \mathrm{mx} 1 \mathrm{~m}$, it had a greater influence on the displacement than the excavation of the 3TT with a $30 \mathrm{~m}$ span. This is most likely due to the much shorter distance to the excavated trench compared to that from the 3TT which was $100 \mathrm{~m}$ away.

To match the displacement from the excavation of the 3TT and the trench, the Young's modulus in the 3D numerical model could be reduced slightly. In that case, the displacement predicted by the numerical model would give a slightly higher value than that obtained from the monitoring data during the critical excavation stage.

It seems also that the model was not able to simulate the effect of blasting activity in the trench. Shock wave from blasting may have introduced additional displacement to the rock mass, which was not modelled by the performed numerical model.

\section{Concluding Remarks}

The Follo Line tunnels were designed to pass at less than $4 \mathrm{~m}$ below the existing Ekeberg road tunnels. This small vertical distance between the new and existing tunnels posed a significant rock mechanics challenge for the planning and 
construction of the new tunnels. The challenge was even more serious due to the requirement that the traffic flow in the existing tunnels had to be maintained at all times.

To deal with this challenge, a rock mechanics tool box was created to assist the planning and construction of the new tunnels. The tool box was a combination of three components: "Investigations", "Numerical modelling", and "Monitoring".

Good collaboration between SINTEF (responsible for the monitoring program and numerical model), the owners of existing road tunnels (Norwegian Road Authority-SVV), and the owners of tunnels under excavation (Bane NOR) was important to find practical solutions related to locations, installation, and continuous monitoring of stress changes and deformations. Early monitoring results gave important values calibrating the $3 \mathrm{D}$ numerical model, making it to be reliable tool.

The most challenging part was the follow-up, and to define thresholds values and action plans in case stress level or the deformation increased too much. As presented in this paper, the changes in the stress level and minor deformations measured were almost perfectly forecasted. It can be concluded that the project was completed successfully without any disturbance to the existing Ekeberg road tunnels. The practical experience gained from the planning and construction of the Follo Line tunnels shows that the tool box would be a reliable and useful method to deal with other future projects.

Acknowledgements The authors would like to express sincerely thanks to Bane NOR for permission to prepare and publish this paper. The authors would also like to thank Dr. Howard Lovenbury (retirement from Black and Veatch, Redhill, United Kingdom) for language improvement of this paper.

Funding Open Access funding provided by SINTEF AS.

Open Access This article is licensed under a Creative Commons Attribution 4.0 International License, which permits use, sharing, adaptation, distribution and reproduction in any medium or format, as long as you give appropriate credit to the original author(s) and the source, provide a link to the Creative Commons licence, and indicate if changes were made. The images or other third party material in this article are included in the article's Creative Commons licence, unless indicated otherwise in a credit line to the material. If material is not included in the article's Creative Commons licence and your intended use is not permitted by statutory regulation or exceeds the permitted use, you will need to obtain permission directly from the copyright holder. To view a copy of this licence, visit http://creativecommons org/licenses/by/4.0/.

\section{Reference}

Aas Jakobsen (2017) Project report - 'Engineering Geology and Hydrogeological Disciplinary Report.

Kruse HC (2017) Bane NOR presentation in "Supplier Meeting 2 February 2017". Available on web: https://www.banenor.no/conte ntassets/c0667e70caf7487f999232196f66cd2d/4.-follo-line-proje ct---hans-christian-kruse_en.pdf. Access on 06 August 2020.

Lawton MF, Andersen HK, Sagen HEW, Jansen JB (2017) Drill and split, a feasible option to careful blasting?, Proceedings of the World Tunnel Congress 2017-Surface challenges-Underground solutions. Bergen, Norway.

SINTEF (2011) Project Report SBF2011F0026 - '3D-Stress measurements for Follobanen Project'.

SINTEF (2012) Project Report SBF2012F0346 - '2D-Stress measurements forFollobanen Project'.

SINTEF (2016) Project Report SBF2016F0315 - '3D-Stress measurements forFollobanen Project'.

Trinh QN, Holmøy HK, Larsen T, Myrvang A (2016) Continued rock stress and displacement measurements combined with numerical modeling as an active, realistic rock engineering tool, RS2016 Symposium, 7th International Symposium on In-Situ Rock Stress, May 10-12, 2016, Tampere, Finland

Trinh QN, Holmøy KH, Sagen HW (2017) Warning system during construction of Follo Line tunnels under the Ekeberg tunnels, National conference - Rock Blasting Conference 23rd-25th November 2017, Oslo, Norway.

Publisher's Note Springer Nature remains neutral with regard to jurisdictional claims in published maps and institutional affiliations. 